\title{
Impacts of global change on water-related sectors and society in a trans-boundary central European river basin - Part 2: from eco-hydrology to water demand management
}

\author{
T. Conradt ${ }^{1}$, M. Kaltofen ${ }^{2}$, M. Hentschel ${ }^{2}$, F. F. Hattermann ${ }^{1}$, and F. Wechsung ${ }^{1}$ \\ ${ }^{1}$ Potsdam Institute for Climate Impact Research, P.O. Box 6012 03, 14412 Potsdam, Germany \\ ${ }^{2}$ Institute for Water Resources Planning and Systems Research (WASY GmbH), Waltersdorfer Strasse 105, 12526 \\ Berlin-Bohnsdorf, Germany
}

Received: 29 January 2007 - Revised: 20 April 2007 - Accepted: 22 May 2007 - Published: 15 June 2007

\begin{abstract}
This second part of the paper presents the details of the eco-hydrological model SWIM simulating the natural water supply and its coupling to WBalMo, a water management model.

Based on the climate scenarios of the STAR model, SWIM simulates the natural water and matter fluxes for the entire Elbe River area. All relevant processes are modelled for hydrotopes and the resulting discharges are accumulated in subbasins. The output data are input for the water management model WBalMo and the quality models Moneris and QSim.

WBalMo takes storage management, inputs and withdrawals into account and analyses how demands by industry, power plants and households will be met at changing natural supply conditions. Some of the first results shall be presented here.
\end{abstract}

\section{Introduction}

A realistic modelling of water amounts and fluxes is of crucial importance for any conclusion concerning impacts of changes in water availability. To answer a question like "How many percent of the output of a certain power plant will presumably have to be cut down in August 2030 due to lack of cooling water?" a modeller needs to know

- the climate change till that year on a regional scale,

- the hydrological boundary conditions like soil profiles, land use, or groundwater recharge coefficients and their interactions, and

- the water management options like reservoir balance plans or distribution policies.

Correspondence to: F. F. Hattermann

(fred.hattermann@pik-potsdam.de)
Each of these input variables may contribute uncertainty to the final answer, and hence it is important to include as much knowledge as possible. Comparably important is the choice of appropriate models which not only decides the validity of process representation but also implicitly determines input data quality by model requirements.

One of the objectives of the GLOWA Elbe project is to make statements on water supply problems not only for a single month or user but for hundreds of users distributed over the whole Elbe River basin for the next 45 years. The models in charge for the detailed hydrological and water management modelling, SWIM and WBalMo, are capable of providing reliable water availabilty scenarios in a high spatial resolution.

In the following section, the methodology of SWIM is presented in detail. SWIM calculates the "natural" water fluxes as if there were no dams or transitions, although accelerated runoff from sealed (urban) surfaces or the effects of open cast mining areas are considered.

WBalMo takes the SWIM output data to include management policies, artificial inputs and withdrawals and computes probabilities of meeting the demands separately for all users in the data base. Section 3 explains the details of the statistical analysis and presents some preliminary results for selected users.

\section{SWIM}

\subsection{Model set up}

SWIM (Soil and Water Integrated Model) was derived from the SWAT (Soil and Water Assessment Tool) model, cf. Arnold et al. (1998); Krysanova et al. (2005). SWIM is a semi-distributed model simulating water fluxes, plant growth, and nutrient cycles based on hydrotopes, areas with uniform land use, soil type, and weather conditions.

Published by Copernicus Publications on behalf of the European Geosciences Union. 


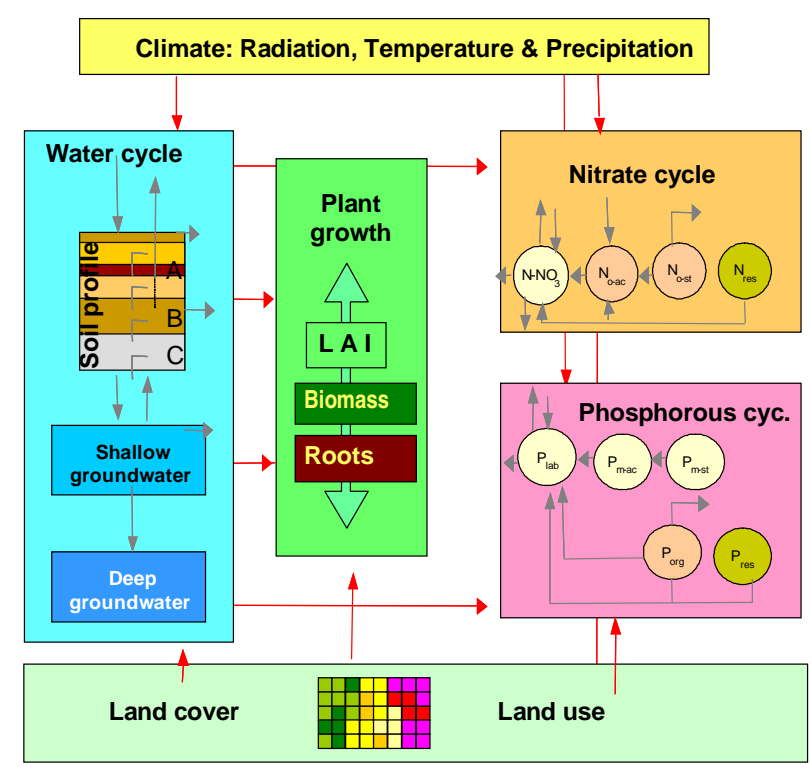

(Krysanova et al. 2000)

Fig. 1. Overview of SWIM modules and the processes modelled.

The hydrotopes were practically determined by overlay of subbasin, land use and soil type maps. Data from climate stations are interpolated to the subbasins, which are also used for discharge routing according to the river system. The Elbe river basin is actually being modelled with more than 45000 hydrotopes in 2278 subbasins. For each hydrotope the processes depicted in Fig. 1 are simulated.

Daily climate data are the driving input for the hydrological part. Soil and vegetation properties, each defined by data sets associated with the respective map units, decide on the allocation of water fluxes. The nitrate and phosporous cycle are modelled simultanuously, but are neglected in the context of this SWIM application, where solely hydrological output is required.

The water fluxes are modelled stepwise, separately for each hydrotope, and based on the daily climate data input. First, air temperature decides whether precipitation enters the system in liquid form or if a snow cover has to be modelled. The amount of rainfall and soil properties decide on the share of direct runoff. Then, the water balance is modelled for each soil layer by computing infiltration and seepage fluxes together with plant water uptake. Water availability, temperature, and radiation govern crop and root growth which in turn decides on plant water demand. Finally, all discharge components are calculated and aggregated for each subbasin.

In a subsequent procedure, river discharges are simulated by adding and routing the single subbasin outputs according to the river system structure on the basis of the Muskingum equations.

Because changes in land use have feedbacks on the hydrological properties of the landscape, the results of RAUMIS and the LandUseScanner, a prognostic tool for the generation of land use scenarios, are iteratively reused for SWIM computations in the form of time period related land use maps.

\subsection{Calibration}

Numerous measured discharge time series from 1981-1990 served as reference to eliminate systematic errors of evapotranspiration, soil conductivity, groundwater discharges, or wave propagation which influence all subbasins. Respective global parameters were adjusted using the Newton parameter optimization algorithm provided by the free software PEST (Parameter ESTimation, Watermark Numerical Computing and S.S. Papadopulos and Associates, Inc., 2007). Finally, Nash-Sutcliffe coefficients of 0.9 could be obtained for the basin outlet gauge Neu Darchau (MQ=714 $\left.\mathrm{m}^{3} \mathrm{~s}^{-1}\right)$.

As all relevant ecosystem processes shall be modelled as exactly as possible, considerable computation efforts are needed due to their complexity. Started on a single CPU (IBM Power4, 1.1 Ghz), SWIM needs approx. $15 \mathrm{~min}$ to simulate one year.

\subsection{Output of subbasin discharges for WBalMo, Moneris,} and QSim

For the coupling of SWIM to the WBalMo model, the subbasin structure of WBalMo was used without major changes. For this purpose, a raster-based GIS module translates elevation data in area specific river parameters. Moreover, it overlays these areas with land use and soil units to hydrotopes. Figure 2 shows in its upper part the numbered SWIM subbasins with the hydrotope structures inside.

Because the discharges are aggregated on subbasin level and routed through the subbasins, it is principally possible to obtain discharge values from each area outlet. However, in most cases WBalMo requires only that share of discharge, which accumulates below inflow area outlets (s.c. end profiles).

Therefore, SWIM was fitted accordingly to accumulate beside the general flow dynamics also those shares of discharge belonging to the subbasins exclusively related to the end profiles (cf. Fig. 2, lower part). Here the flow velocity of the natural dynamics is kept despite the lower partial water quantities.

For the statistical analysis carried out by WBalMo and described below in detail, SWIM was fed with 100 realizations of future climate by the statistical downscaling model STAR (Gerstengarbe and Werner, 2005), each comprising 50 years of daily precipitation, radiation, humidity, minimum, maximum, and mean temperature for 831 locations. These data were interpolated to the SWIM subbasins. For WBalMo, monthly aggregates of the required discharges were provided, 60000 values for each end profile accordingly.

Moneris is the model in charge for landscape nutrient flux modelling within the GLOWA-Elbe Project. As already 


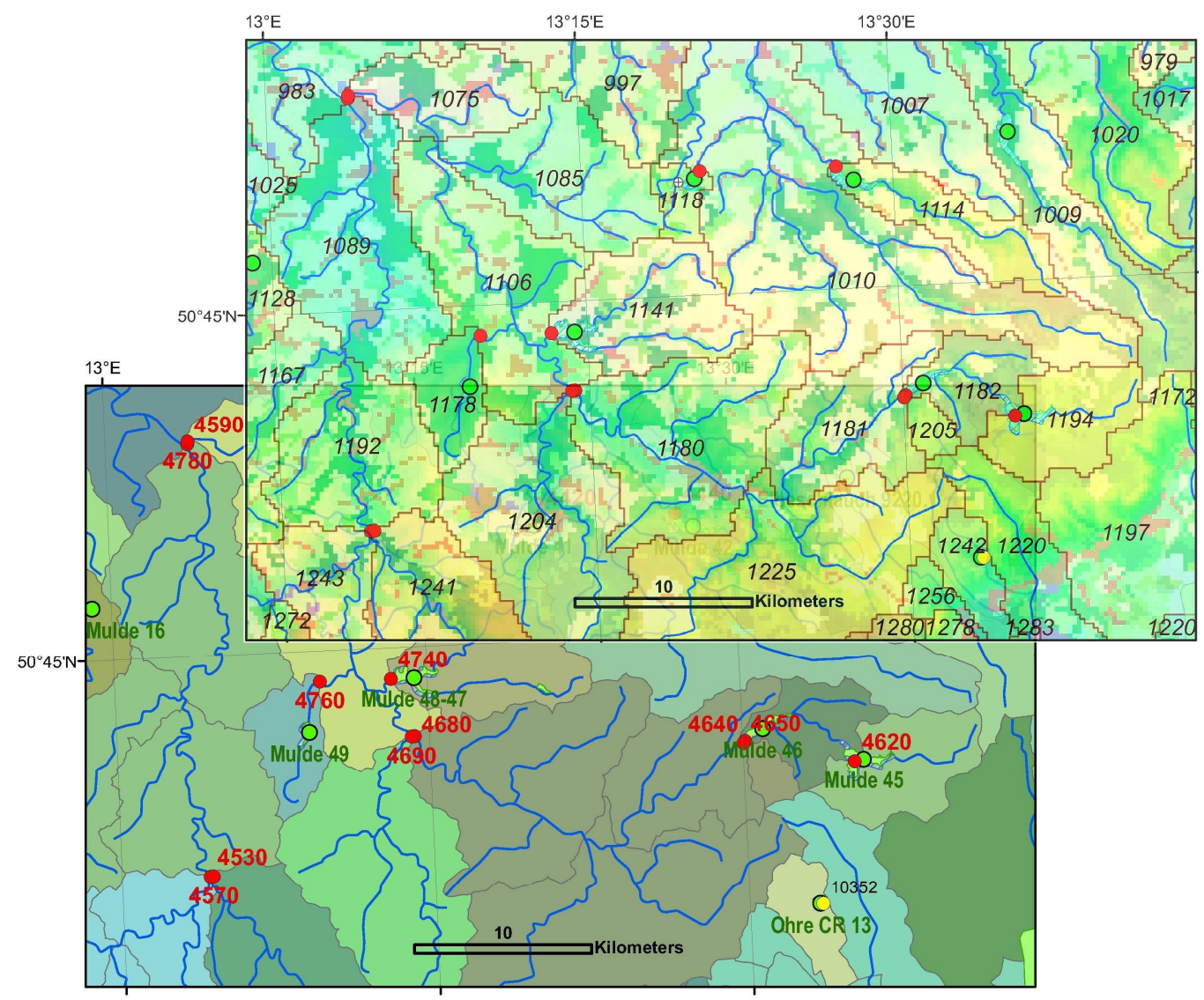

Fig. 2. upper part: Clipout of SWIM's representation of the basin map with numbered subbasins containing hydrotopes. The red points are positions where runoff output is made for WBalMo; at the green points precipitation and evapotranspiration output is made. lower part: The same map clipout in WBalMo's view. The colours indicate the balance areas represented by the data transfer points which have an independent numbering system.

mentioned, the N-and P-modules of SWIM do not contribute to the modelling; only the individual subbasin discharge contributions are required as Moneris input. The runoff values of exemplaric years with average hydrologic conditions are delivered on monthly basis for all 2278 subbasins, separated into surface, intermediate and groundwater component.

Finally, QSim takes daily SWIM outputs of the accumulated discharge in the main channel of the Elbe River. The model simulates in-stream chemistry and biology focusing on algae growth and nutrient exhaustion.

\section{WBalMo}

3.1 Principles of modelling long term water availability and management

Long term planning of water management takes into consideration the balance between water yield and water use, superimposed by water management. Usually long term water management is analysed over planning periods of a number of decades. Over this time span the spatio-temporal distribution of water yield, i.e. discharges and their driving hydrometeorological processes, has to be regarded as a random process.

The user demands, on the other hand, are deterministic in time and space from the planner's point of view. For each time step of the investigated planning horizon and each cross section of the river network in the planning area the water use has to be provided by fixed or varying values or by demand functions. It has to be considered that water demand often depends on:

- time,

- meteorological conditions, and

- socio-economic development.

Goals of water management are, for example, covering the water needs of the users (as municipal water supply, power plants, industry), maintaining minimum discharges 
Table 1. Number and kind of model objects in WBalMo Elbe.

\begin{tabular}{|c|c|c|c|c|c|c|}
\hline WBalMo modules & $\mathrm{BP}$ & $\mathrm{CM}$ & $\mathrm{R}$ & DYN & WU & WET \\
\hline Elbe main stream & 60 & 35 & 2 & 13 & 73 & \\
\hline Eger $(\mathrm{CR})$ & 96 & 63 & 16 & 25 & 218 & \\
\hline Lower Vltava (CR) & 33 & 33 & 9 & 9 & 36 & \\
\hline Upper Vltava (CR) & 28 & 24 & 5 & 8 & 42 & \\
\hline Berounka $(\mathrm{CR})$ & 31 & 31 & 8 & 5 & 40 & \\
\hline Upper/Middle Elbe(CR) & 91 & 60 & 14 & 12 & 185 & \\
\hline Spree-Schwarze Elster & 170 & 120 & 15 & 86 & 336 & $\mathrm{x}$ \\
\hline Wetland Spreewald & 168 & 24 & 0 & 61 & 132 & $\mathrm{x}$ \\
\hline Mulde & 195 & 83 & 15 & 32 & 296 & \\
\hline Saale & 44 & 25 & 5 & 11 & 152 & \\
\hline Bode & 35 & 18 & 6 & 12 & 55 & \\
\hline Weiße Elster & 59 & 35 & 9 & 8 & 84 & \\
\hline Wetland Drömling & 72 & 18 & 0 & 16 & 89 & $\mathrm{x}$ \\
\hline Havel & 192 & 75 & 8 & 33 & 172 & $\mathrm{x}$ \\
\hline Wetland Rhin & 139 & 14 & 0 & 36 & 113 & \\
\hline Berlin & 56 & 21 & 0 & 18 & 146 & $\mathrm{x}$ \\
\hline Nuthe & 70 & 19 & 0 & 15 & 88 & $\mathrm{x}$ \\
\hline Buckau & 25 & 11 & 0 & 11 & 27 & $\mathrm{x}$ \\
\hline Plane & 42 & 10 & 0 & 16 & 49 & $\mathrm{x}$ \\
\hline Gr. Havelländ. Kanal & 43 & 15 & 0 & 11 & 43 & \\
\hline Dosse-Jäglitz & 61 & 16 & 2 & 22 & 63 & $\mathrm{x}$ \\
\hline Lower Elbe & 188 & 82 & 0 & 22 & 148 & $\mathrm{x}$ \\
\hline Total & 1898 & 832 & 114 & 482 & 2587 & \\
\hline
\end{tabular}

(for ecological reasons, but also for navigation), and effective protection against floods.

Starting from these key points the methodology of stochastic long-term management has been developed, mainly for areas characterized by a large demand for water and small available water resources. The used stochastic management models divide the management problem into three parts:

1. stochastic simulation of meteorological and hydrological processes,

2. deterministic simulation of water use processes and water management, and

3. recording of relevant system states.

If the simulation is passed over sufficiently long periods, a statistical analysis of the recorded system states will give satisfactory approximations to the probability distributions sought, for reservoir levels and discharges for certain waterbalance profiles, or safety margins for water provision, for example.

Based on that, the quality of a selected management strategy can be assessed for the investigated river basin and a gradual improvement of this strategy, i.e. the operation of dams, can then be achieved with well-aimed scenario analysis.
3.2 Characteristics of the water management model WBalMo Elbe

Stochastic simulation of meteorological and hydrological processes was described above in Sect. 2. The simulation of the water use processes and water management as well as recording of relevant system states is performed by WBalMo simulation software. It is based on the general methodology described above. The most recent simulation system, used in GLOWA Elbe, is known as WBalMo 3.1 with the possibility to model even very large river basins over $100000 \mathrm{~km}^{2}$ (Kaden et al., 2004).

Using this simulation software a water management model for the whole Elbe river basin was developed, called WBalMo Elbe. The whole model is divided into 22 modules, mainly for Elbe tributaries and major wetlands. Table 1 summarizes their characteristics and the WBalMo Elbe model in total. Each of the modules can be used separately. Modules are defined by the balance profiles (BP), set along the watercourses, the catchments (CM) connected to them, water users (WU), and reservoirs (R).

Water management rules not covered by standard model features are programmed within so called dynamic elements (DYN). High regard is given to wetlands as an import water user (WET). For details about modelling water budget of wetlands see Dietrich et al. (1996). 


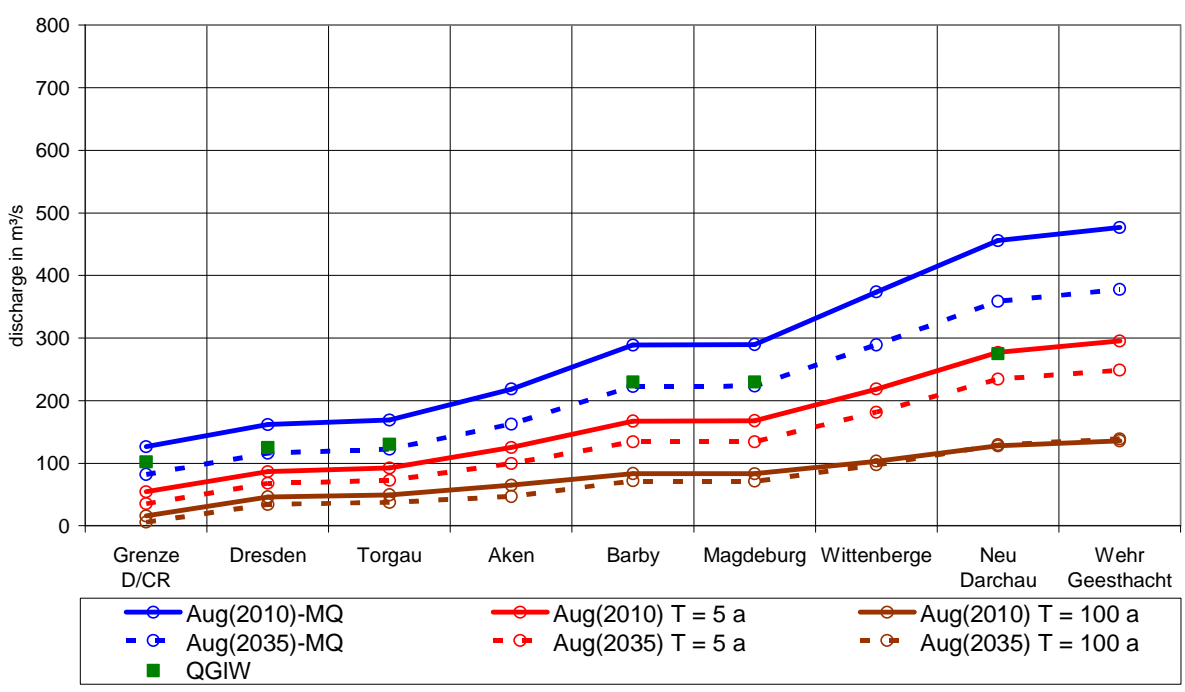

Fig. 3. Longitudinal profile of different discharge values along the Elbe river for the month August compared with according minimum required flow for effective navigation QGIW.

3.3 Preliminary results of long term water availability and management

Water use conflicts exist in the Elbe main river first of all between a given discharge and a minimum required flow, e.g. for effective navigation. In the tributaries the conflict arises between a given discharge and the demand for a certain withdrawal. Because of this, the water use conflict in the main river is analyzed with the help of an longitudinal profile of discharges and minimum required flows, while in the tributaries water demand and water supply is directly compared. For each of these water uses the main questions concerning water availability are:

- What is the extent of the water use conflict under various degrees of drought in the near future?

- How will the water use conflict develop over the whole simulation horizon?

Using statistical analysis of the recorded system states WBalMo Elbe calculates the supplied water on various severities of water shortage as values of different annual return periods. This means that after each of these long-term average number of years the amount of water supply or the discharge will fall below or will at maximum be equal the given value. This analysis can be performed on every period of interest. For each of the periods the calculated values base upon 500 years long time series, provided by SWIM.

In the following graphics for the analysis of the water use conflict the dry month August and return periods of 5, 20 and 100 years at time period 2010 have been chosen. The temporal development of the conflict is shown until 2050 for the return interval of 5 years or for the time period 2035 in comparison to 2010 and the same return intervals.
The results concerning discharges at the main river are shown in Fig. 3, beginning from border inflow to the Elbe weir Geesthacht. The figure contains longitudinal profiles of August, time periods 2010 and 2035. The different profiles refer to: minimum required flow for effective navigation QGIW, average monthly discharges and discharges with return intervals of 5 and 100 years. Comparing the required for navigation flow values with the calculated indicators one can say that the requirements can be met only in flow conditions equal or better than average ones.

In cases of more severe drought situations (increasing return interval) the water use conflict is present. With developing climate change the water use conflict will get worse, comparing time periods 2010 and 2035.

An example for a water use in the tributary Havel is shown in Fig. 4. The figure illustrates water demand and water supply for two scenarios: "STATUS QUO" is based on the values given by the water authority; "SCENARIO 1" assumes more environmental oriented development. The difference of water demand between these scenarios is caused by the different approach to consider the danger of "overwarming" of the river by released cooling water. In the Status-Quoscenario the low demand values in summer already take into account the restricted amount of water, possible to release back into the river after use for cooling because of increased water temperature.

In "SCENARIO 1", these demand estimates are replaced by the value, calculated by a demand function. This function returns the demand required for energy production and the actual withdrawal, considering water temperature. This withdrawal is used for calculating the water resources balance. It is obvious that a water use conflict between demand of cooling water for energy production and the withdrawals, 


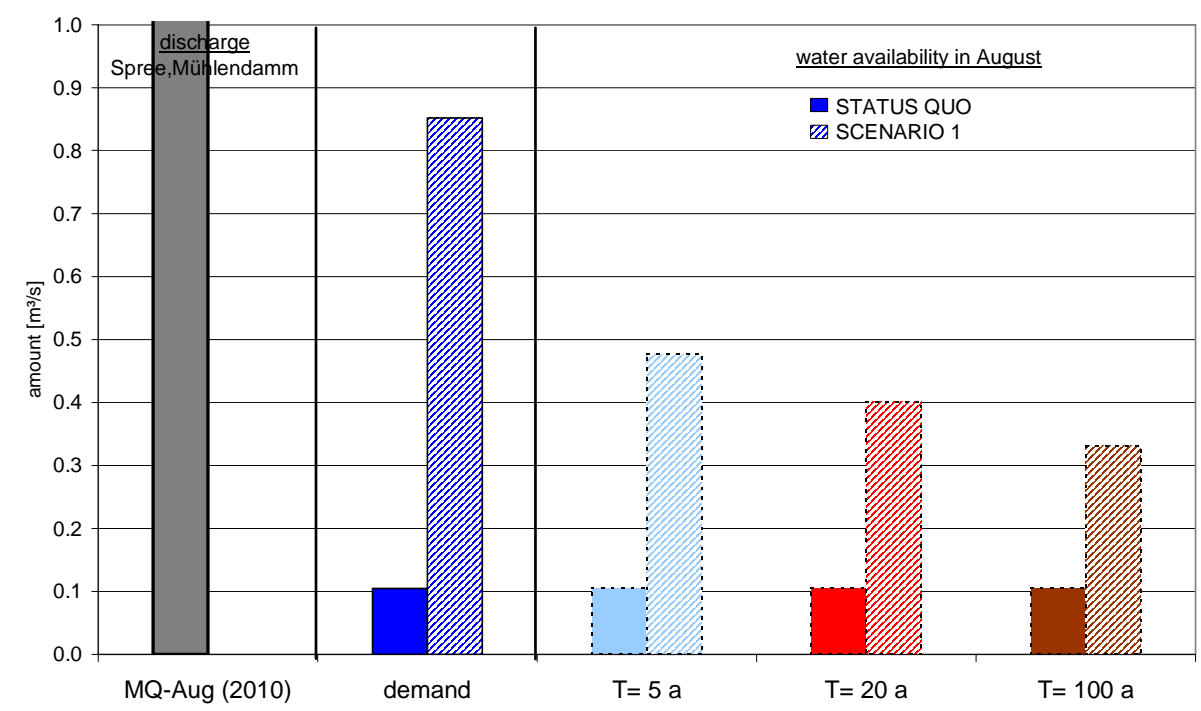

Fig. 4. Water demand and supply of power plant Berlin Mitte.

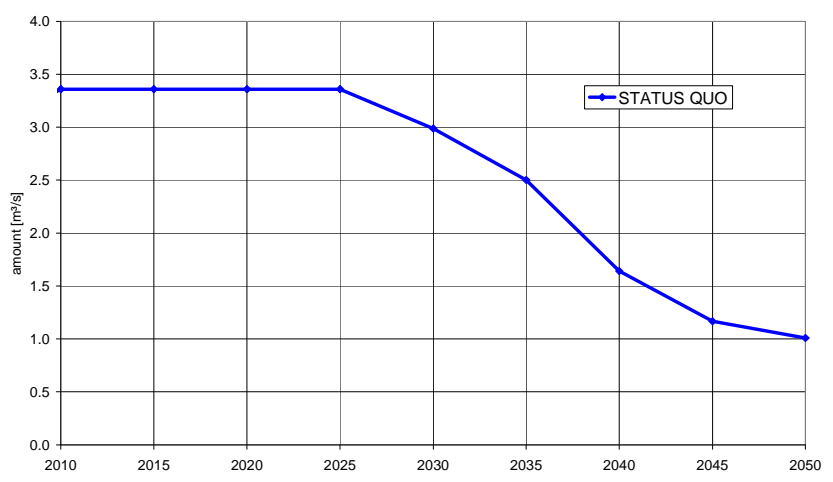

Fig. 5. Development of water use conflict for water work Wienrode at return period $T=5$ a (demand: $3.36 \mathrm{~m}^{3} \mathrm{~s}^{-1}$ ).

possible from both aspects of water temperature and water availability, really takes place. Under hot summer conditions the water supply for the power plant has to be reduced for ecological reasons in order to avoid an overwarming of the river. Consequently, the energy production has to be reduced.

The development of the water use conflict for that kind of water uses (withdrawals) is shown in Fig. 5. In this example the amount of water, provided by the reservoir Rappbode/Bode (Harz mountains, Saale catchment), is significantly decreasing with developing climate warming, while demand stays at the level of $3.36 \mathrm{~m}^{3} \mathrm{~s}^{-1}$. At a return interval of 5 years the water supply is shortened to less than one third of the demand, comparing time periods 2010 and 2050.

Other possible results from WBalMo Elbe are the evaporation from surface water bodies totalised per sub-catchments, the increase of water use of wetlands for controlled drainage and sub-irrigation systems, the failure frequency of one or of a group of reservoirs and other indicators.

\section{Summary and conclusions}

Capabilities of water balance models like WBalMo can be extended to investgations with regard to climate and socioeconomic changes. Therefore a semi-distributed ecohydrological model like SWIM has to be used. This model gives the opportunity to reflect impact of changes in climate and land use on the stream flows. The latter are then used to balance water yield and water demand. First results for Elbe River catchments show various degrees of concern and vulnerability to climate change. Because of the fact that GLOWA Elbe is a running project, please look at www.glowa-elbe.de for further results, including the Czech part of the Elbe river catchment.

Acknowledgements. The authors would like to thank their colleagues H. Apel and C. Hesse who reviewed the text for their support and B. Orlowsky for providing the climate data.

Edited by: K.-E. Lindenschmidt

Reviewed by: H. Apel and C. Hesse

\section{References}

Arnold, J., Srinivasan, R., Muttiah, R., and Williams, J.: Rainfallrunoff modelling for assessing impacts of climate and land-use change, J. Am. Water Resour. As., 34, 73-89, 1998.

Dietrich, O., Dannowski, R., and Quast, J.: GIS-based water balance analyses for fen wetlands, in: International Conference on Application of Geographic Information Systems in Hydrology and Water Resources Management, HydroGIS'96, Vienna, Austria, Vol. of Poster Papers, pp. 83-90, 1996.

Gerstengarbe, F. and Werner, P.: Simulationsergebnisse des regionalen Klimamodells STAR, in: GLOWA-Elbe I - Integrierte Analyse der Auswirkungen des globalen Wandels auf Wasser, 
Umwelt und Gesellschaft im Elbegebiet, edited by: Wechsung, F., Becker, A., and Gräfe, P., Potsdam Institute for Climate Impact Research, Potsdam, Germany, Vol. 95 of PIK report, ISSN 1436-0179, pp. 110-118, 2005.

Kaden, S., Schramm, M., and Redetzky, M.: ArcGRM: Interactive simulation system for water resources planning and management in river basins, in: Research Basins and Hydrological Planning, edited by: Xi, R.-Z., Gu, W.-Z., and Seiler, K.-P., Taylor \& Francis, London, UK, ISBN 90-5809-611-4, pp. 185-192, 2004.
Krysanova, V., Hattermann, F., and Wechung, F.: Development of the ecohydrological model SWIM for regional impact studies and vulnerability assessment, Hydrol. Processes, 19, 763-783, 2005.

Watermark Numerical Computing and S.S. Papadopulos and Associates, Inc.: PEST online resource, http://www.sspa.com/pest/ index.htm, current user manual by Doherty, J., 5th ed., 336 pp., 2004, UNIX PEST version 11.2, 2007. 